\title{
Comparison of Pulse Oximetry and Capnography Monitoring with Arterial Blood Gases Parameters among Postoperative Pediatric Cardiac Surgeries at a University Hospital
}

\author{
Nahla Shaaban Khalil ${ }^{1 *}$, Mohamed-Adel Fetouh El Gamal', Marwa Fathallah Mostafa ${ }^{3}$ and Mona Abd El \\ Aziz El Bialy ${ }^{4}$
}

${ }^{1}$ Assist professor at Critical Care and Emergency Nursing, Cairo University, Egypt

${ }^{2}$ Professor at Congenital and Pediatric Cardiac Surgery,faculty of medicine, mansoura university

${ }^{3}$ Lecturer at critical care and Emergency Nursing ,Mansoura University

${ }^{4}$ Registered Nurse at Mansoura University Child Hospital, Egypt

*Corresponding author: Nahla Shaaban Khalil, Assist professor at Critical Care

and Emergency Nursing, Cairo University, Egypt.

Received Date: April 01, 2019

Published Date: April 24, 2019

\begin{abstract}
Background: Pediatric patients undergone mechanical ventilation after cardiac surgeries need rapid and reliable evaluation of their respiratory status. Monitoring of pulse oximetery and capnography as a surrogate, noninvasive measurement of arterial oxygen saturation $\left(\mathrm{SaO}_{2}\right)$ and arterial carbon dioxide tension $\left(\mathrm{PaCO}_{2}\right)$ became important respiratory monitoring.

Aim of the study: Was to compare pulse oximetery and capnography monitoring values with arterial blood gas parameters among postoperative pediatric cardiac surgeries.

Subjects and Methods: A descriptive correlational design was adopted utilizing a convenience sample of 88 pediatric patients with cardiac anomalies who undergoing total repair surgeries, intubated for mechanical ventilation and had an indwelling arterial catheter as part of their evaluation in postoperative period were included in the study. Patient's demographic, clinical relevant data as well as invasive and noninvasive monitoring of arterial oxygen saturation and arterial carbon dioxide partial pressure were utilized in data collection

Results: Statistical analysis demonstrated mean differences between $\mathrm{SaO}_{2}$ and $\mathrm{SpO}_{2}(98.2 \pm 1.6 \%$ and $97.5 \pm 2.4 \%$ respectively; $\mathrm{p}=0.024)$ ) as well as the mean difference between $\mathrm{PaCO}_{2}$ and $\mathrm{PetCO}_{2}(36.9 \pm 6.9 \mathrm{mmHg}$ and $33.1 \pm 7.7 \mathrm{mmHg}$ respectively; $\mathrm{p}<0.001)$. As well, a significant positive correlation was found between the mean $\mathrm{SaO}_{2}$ and $\mathrm{SpO}_{2}(\mathrm{r}=0.935, \mathrm{p}<0.001)$ as well as, between the mean $\mathrm{PaCO}_{2}$ and $\mathrm{PetCO}_{2}(\mathrm{r}=0.930, \mathrm{p}<0.001)$.

Conclusion: It can be concluded that $\mathrm{SpO}_{2}$ and $\mathrm{EtCO}_{2}$ values are positively correlated with $\mathrm{SaO}_{2}$ and $\mathrm{PaCO}_{2}$ in mechanically ventilated pediatric patients after cardiac surgeries. Therefore $\mathrm{SpO}_{2}$ and $\mathrm{EtCO}_{2}$ monitoring can be used as a continuous, non-invasive predictor for $\mathrm{SaO}_{2}$ and $\mathrm{PaCO}_{2}$.

Keywords: Pulse oximetry; Capnography; Arterial blood gases; Congenital heart defects
\end{abstract}

\section{Introduction}

Pediatric patients on mechanical ventilation after cardiac surgeries are in a vulnerable period that requiring continuous and comprehensive monitoring and every single change in the patient's physiological variables are taken into account [1]. Pediatric patients who undergo cardiac surgery are at risk for developing respiratory insufficiency after cardiac surgery as a result of the effects of general anesthesia, the surgical procedure and inflammatory response to cardiopulmonary bypass, therefore, they need careful management of mechanical ventilation for supporting oxygenation and ventilation [2]. Arterial blood gases is the gold standard for the assessment of oxygenation and ventilation [3]. However, there are several complications and limitations of arterial blood sampling which can arise from arterial puncture or presence of indwelling arterial catheter especially in pediatrics which includes local hematoma, artery vasospasm, infection at 
the puncture site, hemorrhage, arterial occlusion, air or thrombus embolism and local pain. Moreover, sampling is intermittent, timeconsuming and delay in obtaining results which can affect the clinical decision about patient management [4]. Pulse oximetry and capnography technology became monitoring standard in critical care units and commonly useful for accompanying mechanical ventilation management [5]. Pulse oximetry is an effective method for continuous and non-invasive monitoring of arterial oxygen saturation using a probe attached to different body sites which can lead to a more rapid treatment of serious hypoxemia, used for titration of inspired oxygen and wean mechanical ventilation [6]. Capnography is a useful noninvasive and continuous monitoring tool for arterial carbon dioxide tension. $\mathrm{PetCO}_{2}$ monitoring provides an assessment of the adequacy of ventilation also it can be used for confirming correct ETT placement, early warning for loss of the ventilator circuit integrity and changes in cardiopulmonary status [7]. Hence, the direction towards non-invasive methods for continuous monitoring of $\mathrm{SaO}_{2}$ and $\mathrm{PaCO}_{2}$ values should be used followed to facilitate clinical diagnosis and treatment. In addition to avoiding complications related to invasive monitoring and helps in reducing medical cost [8].

\section{The Aim of the Study}

The main aim of this study was to compare pulse oximetry and capnography $\left(\mathrm{SpO}_{2}\right.$ and $\left.\mathrm{EtCO}_{2}\right)$ monitoring values with arterial blood gas parameters $\left(\mathrm{SaO}_{2}\right.$ and $\left.\mathrm{PaCO}_{2}\right)$ among postoperative mechanically ventilated pediatric patients after cardiac surgeries.

\section{Subjects and Methods}

A prospective descriptive correlational design was used to conduct this study. The study was conducted at the pediatric cardiac surgery intensive care unit Mansoura University Child Hospital (MUCH). A Convenience sample of 88 pediatric patients with cardiac anomalies who undergoing total repair surgeries, intubated for mechanical ventilation and had an indwelling arterial catheter as part of their evaluation in postoperative period were included in the study. The exclusion criteria included pediatric patients with low cardiac output, palliative surgeries for cyanotic congenital heart disease, extreme peripheral vasoconstriction and high doses of vasoactive drugs, intravascular dyes, seizures and severe anemia.

\section{Tools of data collection}

Demographic data included data related to age, gender, weight, diagnosis and operation type. Moreover, clinical relevant data included monitoring of Cardiovascular parameters such as heart rate (HR), mean arterial pressure (MAP), pulse pressure (PP),core temperature. As well, Ventilator parameters were monitored including as mode of ventilator, respiratory rate (RR), fraction of inspired oxygen $\left(\mathrm{FiO}_{2}\right)$, post end expiratory pressure (PEEP), peak inspiratory pressure (PIP), pressure support (PS) and I: E ratio. Finally, checking the hemoglobin level

Tool (2) : invasive and noninvasive monitoring of arterial oxygen saturation and arterial carbon dioxide partial pressure:
Invasive monitoring consisted of $\mathrm{SaO}_{2}$ and $\mathrm{PaCO}_{2}$ in addition to $\mathrm{PH}$ and arterial blood partial pressure of oxygen $\left(\mathrm{paO}_{2}\right)$. On the other hand, Noninvasive monitoring included of $\mathrm{SpO}_{2}$ and $\mathrm{PetCO}_{2}$.

\section{Validity and Reliability of Tool}

Content validity of tools was revised and ensured by a panel of five experts in the field of critical care nursing and medical specialties based on the expert's opinions; the researcher developed the last validated form of the tools. The developed and validated a tool for invasive and noninvasive monitoring of arterial oxygen saturation and arterial carbon dioxide partial pressure comparison tool was tested for reliability using Cronbach's test and its value was 0.823 .

\section{Pilot Study}

A pilot study was done on 10 subjects to test feasibility and clarity of the tools and the necessary modifications were done prior data collection such as in pediatrics, pressure-controlled ventilation was mostly used rather than volume controlled ventilation so tidal volume parameter was canceled. The subjects included in the pilot study were excluded from the whole study sample.

\section{Ethical Consideration}

Ethical approval was obtained from the research ethics of the Faculty of Nursing at Mansoura University. An official consent was obtained from hospital administrators at Child Hospital Mansoura University to initiate data collection. Informed consent was obtained from the child's mother before enrollment in the study after explaining the purpose of the study and emphasized that participation in the study is voluntary.

\section{Data Were Collected in Two Phases}

\section{Phase I: Preparatory phase}

Adequate preparations for the study subjects and proper calibration for pulse oximetry and capnography were performed as well; the accuracy of the detected waveform by both devices was verified.

\section{Phase II: Implementation phase}

The readings were taken after (15-20) minutes of any procedure affecting ABGs results such as after transportation from operating room to ICU and every time changes in ventilator parameters had been performed as the child should be in a respiratory steady state. Later, the simultaneous recording of physiological parameters was recorded before taking $\mathrm{SpO}_{2}$ and $\mathrm{PetCO}_{2}$ reading. Then, $\mathrm{SpO}_{2}$ and Pet $\mathrm{CO}_{2}$ reading were obtained using monitor (model Infinity Kappa, Drager Medical Systems, Inc. Danvers, MA01923 USA), exhaled $\mathrm{CO}_{2}$ was continuously monitored through available mainstream capnography and $\mathrm{SO}_{2}$ was monitored through finger probe later, arterial blood sample was drawn from the arterial catheter (within 2 minutes) for $\mathrm{SaO}_{2}$ and $\mathrm{PaCO}_{2}$ analysis utilizing arterial blood gas analyzer (Siemens, RAPID point 500, Ny10591-5097 USA).Then, the reading was recorded. 


\section{Data Analysis}

All statistical analyses were performed using SPSS for windows version 20.0 (SPSS, Chicago, IL). Data were tested for normality of distribution prior to any calculations. Continuous data were expressed in mean \pm standard deviation (SD). Categorical data were expressed in number and percentage. The comparisons were determined using Student's t-test for variables with continuous data while Chi-square test was used for comparison of variables with categorical data. The correlations were tested using the correlation coefficient test. Statistical significance was set at $\mathrm{p}<0.05$.

\section{Result}

A total 88 mechanically ventilated pediatric patients were studied. The data collection took approximately ten months from beginning of May 2016 to end of February2017.The age of the studied subjects ranged from 3 months to 143 months, median of the age was 13 months (interquartile range [IQR] 31 months) nearly half of them were infants. As well, more than half of the subjects, (58\%) were male while, (42\%) were female their body weight range from $4 \mathrm{~kg}-50 \mathrm{~kg}$ (mean $12.5 \pm 10.6 \mathrm{~kg}$ ). It found that two thirds of children hadn't cyanosis pre-operative (68.2\%) while, third $(28 \%)$ of children had cyanosis pre-operative. The baseline physiological variables are summarized in Table 1.

The correlation between $\mathrm{SaO}_{2}$ and $\mathrm{SpO}_{2} \quad(\mathrm{r}=0.935$, $\mathrm{p}<0.001$ ) is shown in Figure 1, as well as the positive correlation between $\mathrm{PaCO}_{2}$ and $\mathrm{ETCO}_{2}(\mathrm{r}=0.930, \mathrm{p}<0.001)$ is shown in Figure 2. The effect of studied variables on the mean differences between $\left(\mathrm{SaO}_{2}-\mathrm{SPO}_{2}\right)$ and $\left(\mathrm{PaCO}_{2}-\mathrm{PetCO}_{2}\right)$ is illustrated in Table $3 \& 7$ which showed the mean difference between $\mathrm{SaO}_{2}-$ $\mathrm{SPO}_{2}$ was significantly correlated to heart rate $(\mathrm{P}=0.048)$; PIP $(\mathrm{P}=0.004) ; \mathrm{PaO}_{2}(\mathrm{P}=0.003) ; \mathrm{SaO}_{2}(\mathrm{P}=0.039)$ and $\mathrm{SpO}_{2}(\mathrm{P}<0.001)$. Moreover, the mean difference between $\mathrm{PaCO} 2$ andPetCO2 was also significantly correlated to PIP ( $\left.\mathrm{P}=0.013) ; \mathrm{PaO}_{2} \mathrm{P}=0.042\right)$ and $\mathrm{PetCO}_{2}(\mathrm{P}<0.001)$.

Table 1: The baseline physiological variables $(n=88)$.

\begin{tabular}{|c|c|}
\hline Variables & Mean \pm SD \\
\hline Heart rate (beat /min) & $142.0 \pm 22.8$ \\
\hline MAP (mmHg) & $75.6 \pm 11.3$ \\
\hline Pulse pressure (mmHg) & $48.5 \pm 13.0$ \\
\hline Core temperature $\left({ }^{\circ} \mathrm{C}\right)$ & $37.3 \pm 0.5$ \\
\hline Respiratory rate (breath /minute) & $29.6 \pm 7.4$ \\
\hline Pressure support $\left(\mathrm{cmH}_{2} \mathrm{O}\right)$ & $13.0 \pm 0.5$ \\
\hline $\mathrm{PIP}\left(\mathrm{cmH}_{2} \mathrm{O}\right)$ & $20.3 \pm 3.6$ \\
\hline $\operatorname{PEEP}\left(\mathrm{cmH}_{2} \mathrm{O}\right)$ & $5.3 \pm 1.0$ \\
\hline $\mathrm{FiO}_{2}(\%)$ & $41.8 \pm 8.3$ \\
\hline Hemoglobin level & $12.7 \pm 1.2$ \\
\hline $\mathrm{PaO}_{2} \mathrm{mmHg}$ & $158.6 \pm 57.0$ \\
\hline $\mathrm{PH}$ & $7.45 \pm 0.06$ \\
\hline $\mathrm{SaO}_{2} \%$ & $98.2 \pm 1.6$ \\
\hline $\mathrm{PaCO}_{2} \mathrm{mmHg}$ & $36.9 \pm 6.9$ \\
\hline $\mathrm{SpO}_{2} \%$ & $97.5 \pm 2.4$ \\
\hline $\mathrm{PetCO}_{2} \mathrm{mmHg}$ & $33.1 \pm 7.7$ \\
\hline
\end{tabular}

Table 2: Comparison between invasive and non-invasive monitoring of oxyhemoglobin saturation and carbon dioxide tension.

\begin{tabular}{|c|c|c|c|}
\hline Readings & $\mathbf{X} \pm$ SD & Range & $\begin{array}{c}\text { Test of } \\
\text { signifcance }\end{array}$ \\
\hline $\mathrm{SaO}_{2}(\%)$ & $98.2 \pm 1.6$ & $92-100$ & \\
\hline $\mathrm{SpO}_{2}(\%)$ & $97.5 \pm 2.4$ & $90-100$ & $\mathrm{t}=2.277$ \\
\hline Mean $\left(\mathrm{SaO}_{2}-\mathrm{SpO}_{2}\right)$ difference $(\%)$ & $0.7 \pm 1.1$ & & $\mathrm{p}=0.024$ \\
\hline $\mathrm{PaCO}_{2}(\mathrm{mmHg})$ & $36.9 \pm 6.9$ & $25-59$ & \\
\hline $\mathrm{PetCO}_{2}(\mathrm{mmHg})$ & $33.1 \pm 7.7$ & $20-57$ & $\mathrm{t}=3.448$ \\
\hline $\begin{array}{c}\text { Mean }\left(\mathrm{PaCO}_{2}-\mathrm{PetCO}\right) \text { difference } \\
(\mathrm{mmHg})\end{array}$ & $3.8 \pm 2.9$ & & $\mathrm{p}<0.001$ \\
\hline
\end{tabular}

* $p$ value significant $\leq 0.05$

Table 3: The effect of demographic characteristics on the mean difference between $\left(\mathrm{SaO}_{2}-\mathrm{SPO}_{2}\right)$ and $\left(\mathrm{PaCO}_{2}-\mathrm{PetCO}_{2}\right)$.

\begin{tabular}{|c|c|c|c|c|}
\hline \multicolumn{3}{|c|}{$\mathrm{SaO}_{2}-\mathrm{SPO}_{2}$ Difference } & \multicolumn{2}{|c|}{$\mathrm{PaCO}_{2}-\mathrm{PetCO}_{2}$ Difference } \\
\hline \multicolumn{2}{|c|}{ Mean \pm SD } & $\begin{array}{c}\text { Signifi- } \\
\text { cance }\end{array}$ & $\begin{array}{l}\text { Mean } \\
\pm \text { SD }\end{array}$ & Significance \\
\hline Age & \multirow{2}{*}{$0.95 \pm 1.05$} & & & \multirow{6}{*}{$\begin{array}{l}F=2.382 \\
P=0.075\end{array}$} \\
\hline Infant & & & $4.3 \pm 0.9$ & \\
\hline Toddler & $0.5 \pm 0.98$ & & $2.5 \pm 2.6$ & \\
\hline Preschool & $0.82 \pm 1.3$ & $\mathrm{~F}=1.434$ & $4.5 \pm 2.3$ & \\
\hline School & $0.42 \pm 0.90$ & $\mathrm{P}=0.239$ & $3.6 \pm 3.7$ & \\
\hline Gender & \multirow{2}{*}{$0.84 \pm 1.10$} & \multirow{2}{*}{$\mathrm{t}=1.173$} & \multirow{2}{*}{$4.0 \pm 2.7$} & \\
\hline Male & & & & $\mathrm{t}=0.844$ \\
\hline Female & $0.57 \pm 1.07$ & $\mathrm{P}=0.244$ & $3.5 \pm 3.0$ & $\mathrm{P}=0.401$ \\
\hline Weight & \multirow{2}{*}{$0.63 \pm 1.3$} & & \multirow{2}{*}{$2.7 \pm 3.7$} & \multirow{5}{*}{$\begin{array}{l}F=1.619 \\
P=0.204\end{array}$} \\
\hline Under weight & & & & \\
\hline Normal weight & $0.78 \pm 1.1$ & $\mathrm{~F}=0.266$ & $4.0 \pm 2.6$ & \\
\hline Over weight & $0.50 \pm 0.84$ & $\mathrm{P}=0.767$ & $4.3 \pm 1.0$ & \\
\hline $\begin{array}{c}\text { Pre-Operative } \\
\text { Cyanosis }\end{array}$ & \multirow[t]{2}{*}{$0.65 \pm 1.05$} & \multirow[t]{2}{*}{$\mathrm{t}=0.973$} & \multirow[t]{2}{*}{$3.7 \pm 2.8$} & \\
\hline No & & & & $\mathrm{t}=0.534$ \\
\hline Yes & $0.89 \pm 1.16$ & $\mathrm{P}=0.333$ & $4.0 \pm 3.0$ & $\mathrm{P}=0.595$ \\
\hline
\end{tabular}

Table 4: The effect of cardiovascular variables on the mean difference between $\mathrm{SaO}_{2}-\mathrm{SPO}_{2}$ and $\mathrm{PaCO}_{2}-\mathrm{PetCO}_{2}$.

\begin{tabular}{|c|c|c|c|c|}
\hline \multicolumn{2}{|c|}{$\mathrm{SaO}_{2}-\mathrm{SPO}_{2}$ difference } & \multicolumn{2}{c|}{$\mathrm{PaCO}_{2}-$ PetCO $_{2}$ differ- } \\
ence
\end{tabular}




\begin{tabular}{|c|c|c|c|c|}
\cline { 1 - 4 } MAP & $2.0 \pm 0.0$ & & $5.5 \pm 0.7$ & \\
\cline { 1 - 4 } Low & $1.00 \pm 1.10$ & $\mathrm{~F}=1.918$ & $4.2 \pm 2.6$ & $\mathrm{~F}=0.539$ \\
\hline Normal & $0.65 \pm 1.08$ & $\mathrm{P}=0.153$ & $3.7 \pm 2.9$ & $\mathrm{P}=0.585$ \\
\hline $\begin{array}{c}\text { Core Tem- } \\
\text { perature }\end{array}$ & $1.4 \pm 1.0$ & & $5.0 \pm 1.4$ & \\
\cline { 1 - 2 } Low & $0.6 \pm 1.1$ & $\mathrm{~F}=2.229$ & $3.6 \pm 3.0$ & $\mathrm{~F}=1.016$ \\
\cline { 1 - 4 } Normal & $1.0 \pm 1.1$ & $\mathrm{P}=0.114$ & $4.3 \pm 2.5$ & $\mathrm{P}=0.366$ \\
\hline High & & & \\
\hline
\end{tabular}

Table 5: The effect of mechanical ventilator variables on the mean difference between $\mathrm{SaO}_{2}-\mathrm{SPO}_{2}$ and $\mathrm{PaCO}_{2}-\mathrm{PetCO}_{2}$.

\begin{tabular}{|c|c|c|c|c|}
\hline \multicolumn{3}{|c|}{$\mathrm{SaO}_{2}-\mathrm{SPO}_{2}$ difference } & \multicolumn{2}{|c|}{$\mathrm{PaCO}_{2}-\mathrm{PetCO}_{2}$ Difference } \\
\hline \multicolumn{2}{|c|}{ Mean \pm SD } & Significance & Mean \pm SD & Significance \\
\hline $\begin{array}{c}\text { Respiratory } \\
\text { rate }\end{array}$ & \multirow[t]{2}{*}{$0.74 \pm 1.1$} & \multirow[t]{2}{*}{$t=0.160$} & \multirow[t]{2}{*}{$3.8 \pm 2.9$} & \multirow[t]{2}{*}{$\mathrm{t}=0.114$} \\
\hline Normal & & & & \\
\hline Tachypnea & $0.69 \pm 1.1$ & $\mathrm{P}=0.873$ & $3.7 \pm 2.8$ & $\mathrm{p}=0.910$ \\
\hline PIP $\left(\mathrm{cmH}_{2} \mathrm{O}\right)$ & \multirow{2}{*}{$0.5 \pm 1.1$} & \multirow{2}{*}{$\mathrm{t}=2.956$} & \multirow{2}{*}{$3.3 \pm 3.1$} & \multirow{2}{*}{$t=2.543$} \\
\hline $15-20$ & & & & \\
\hline$>20$ & $1.2 \pm 0.9$ & $\mathrm{P}=0.004$ & $4.9 \pm 1.8$ & $\mathrm{P}=0.013$ \\
\hline PEEP $\left(\mathrm{cm} \mathrm{H}_{2} \mathrm{O}\right)$ & \multirow{2}{*}{$0.7 \pm 1.1$} & \multirow{2}{*}{$t=0.623$} & \multirow{2}{*}{$3.6 \pm 2.9$} & \multirow{2}{*}{$\mathrm{t}=0.877$} \\
\hline$<5$ & & & & \\
\hline$>5$ & $0.9 \pm 1.1$ & $\mathrm{P}=0.535$ & $4.2 \pm 2.5$ & $\mathrm{P}=0.383$ \\
\hline $\mathrm{FiO}_{2}(\%)$ & \multirow{2}{*}{$0.8 \pm 1.1$} & \multirow{2}{*}{$t=1.514$} & \multirow{2}{*}{$3.8 \pm 3.0$} & \multirow{2}{*}{$\mathrm{t}=0.094$} \\
\hline$<50$ & & & & \\
\hline$>50$ & $0.3 \pm 0.9$ & $\mathrm{P}=0.134$ & $3.7 \pm 2.2$ & $\mathrm{P}=0.925$ \\
\hline I.E ratio & \multirow{2}{*}{$0.8 \pm 1.1$} & \multirow{2}{*}{$\mathrm{t}=0.809$} & \multirow{2}{*}{$3.7 \pm 3.1$} & \multirow{2}{*}{$t=0.088$} \\
\hline $1: 1-1: 2$ & & & & \\
\hline$>1: 2$ & $0.6 \pm 1.1$ & $\mathrm{P}=0.421$ & $3.8 \pm 2.7$ & $\mathrm{P}=0.930$ \\
\hline
\end{tabular}

Table 6: The effect of arterial blood gases parameter on the mean difference between $\mathrm{SaO}_{2}-\mathrm{SPO}_{2}$ and $\mathrm{PaCO}_{2}-\mathrm{PetCO}_{2}$.

\begin{tabular}{|c|c|c|c|c|}
\hline \multicolumn{3}{|c|}{$\mathrm{SaO}_{2}-\mathrm{SPO}_{2}$ difference } & \multicolumn{2}{|c|}{$\mathrm{PaCO}_{2}-\mathrm{PetCO}_{2}$ Difference } \\
\hline \multicolumn{2}{|c|}{ Mean \pm SD } & \multirow[t]{3}{*}{ Significance } & \multirow{3}{*}{$\begin{array}{c}\text { Mean } \pm \text { SD } \\
5.8 \pm 0.4\end{array}$} & \multirow{3}{*}{$\begin{array}{c}\text { Significance } \\
\text { F=3.286 }\end{array}$} \\
\hline $\mathrm{PaO}_{2} \mathrm{mmHg}$ & \multirow{2}{*}{$2.0 \pm 0.01$} & & & \\
\hline$<80$ & & & & \\
\hline $80-100$ & $1.0 \pm 0.01$ & $F=6.731$ & $5.0 \pm 0.4$ & \\
\hline$>100$ & $0.46 \pm 1.09$ & $\mathrm{P}=0.003$ & $3.3 \pm 3.0$ & $\mathrm{P}=0.042$ \\
\hline $\mathrm{SaO}_{2} \%$ & \multirow{2}{*}{$2.0 \pm 0.01$} & \multirow{2}{*}{$t=2.097$} & \multirow{2}{*}{$5.7 \pm 0.6$} & \multirow{2}{*}{$t=1.180$} \\
\hline$<95$ & & & & \\
\hline$\geq 95$ & $0.68 \pm 1.1$ & $\mathrm{P}=0.039$ & $3.7 \pm 2.9$ & $\mathrm{P}=0.241$ \\
\hline $\mathrm{PaCO}_{2} \mathrm{mmHg}$ & \multirow{2}{*}{$0.69 \pm 0.96$} & \multirow[b]{3}{*}{$\mathrm{F}=0.044$} & \multirow{2}{*}{$3.7 \pm 2.0$} & \multirow{3}{*}{$\mathrm{F}=0.327$} \\
\hline$<35$ & & & & \\
\hline $35-45$ & $0.75 \pm 1.20$ & & $3.4 \pm 3.4$ & \\
\hline$>45$ & $0.78 \pm 1.09$ & $\mathrm{P}=0.957$ & $4.2 \pm 2.8$ & $\mathrm{P}=0.722$ \\
\hline pH & \multirow{2}{*}{$1.75 \pm 0.5$} & \multirow{3}{*}{$\mathrm{F}=1.885$} & \multirow{2}{*}{$5.5 \pm 0.6$} & \multirow{3}{*}{$\mathrm{F}=1.413$} \\
\hline$<7.35$ & & & & \\
\hline $7.35-7.45$ & $0.69 \pm 1.16$ & & $3.4 \pm 3.3$ & \\
\hline$>7.45$ & $0.67 \pm 1.01$ & $\mathrm{P}=0.158$ & $4.1 \pm 2.3$ & $\mathrm{P}=0.249$ \\
\hline
\end{tabular}

Table 7: The effect of $\mathrm{SpO}_{2}$ values on the mean difference between $\mathrm{SaO}_{2}$ $-\mathrm{SPO}_{2}$ difference and the effect of $\mathrm{PetCO}_{2}$ values on the mean difference between $\mathrm{PaCO}_{2}-\mathrm{PetCO}_{2}$.

\begin{tabular}{|c|c|c|}
\hline \multicolumn{3}{|c|}{$\mathrm{SaO}_{2}-\mathbf{S P O}_{2}$ Difference } \\
\hline $\mathbf{S p O}_{2} \%$ & Mean \pm SD & Significance \\
\hline$<95$ & $2.0 \pm 0.01$ & $\mathrm{t}=4.890$ \\
\hline$\geq 95$ & $0.53 \pm 1.03$ & $\mathrm{P}<0.001$ \\
\hline \multicolumn{3}{|c|}{ PaCO $_{2}-$ PetCo $_{2}$ Difference } \\
\hline PetCO $_{2}$ mmHg & Mean \pm SD & Significance \\
\hline$<35$ & $4.8 \pm 0.96$ & \multirow{2}{*}{$\mathrm{F}=12.509$} \\
\hline $35-45$ & $2.3 \pm 3.8$ & $\mathrm{P}<0.001$ \\
\hline$>45$ & $4.3 \pm 0.75$ & \\
\hline
\end{tabular}

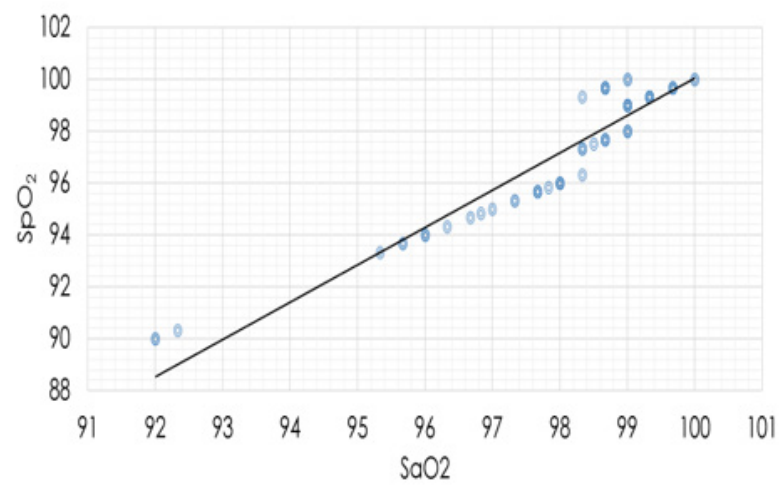

Figure 1: Correlation between $\mathrm{SaO}_{2}(\%)$ and $\mathrm{SpO}_{2}(\%)$, Showing a significant correlation $(r=0.935, p<0.001)$.

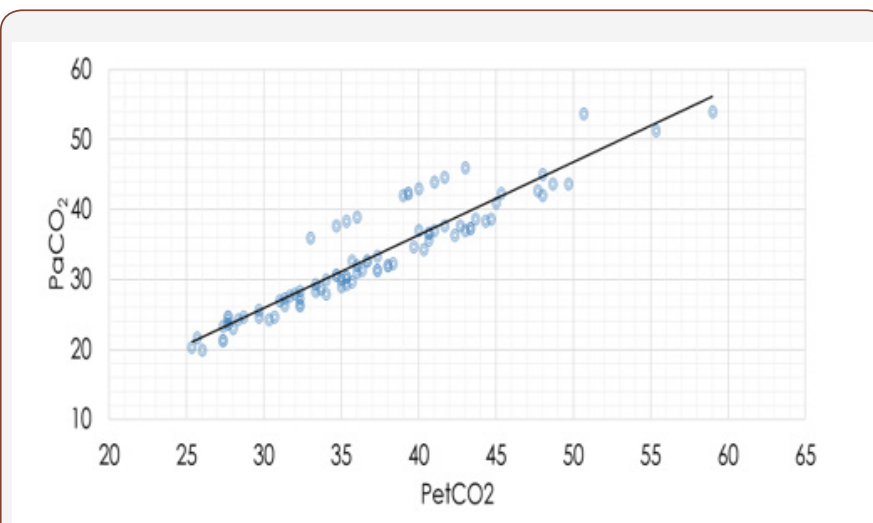

Figure 2: Correlation between $\mathrm{PaCO}_{2}(\mathrm{mmHg})$ and $\mathrm{ETCO}_{2}$ $(\mathrm{mmHg})$, Showing a significant correlation $(r=0.930, p<0.001)$.

\section{Discussion}

The analysis of data in the present study showed that there was a significant difference between the mean $\mathrm{SaO} 2$ and the mean $\mathrm{SpO}_{2}$ as well as, between the mean $\mathrm{PaCO}_{2}$ and the mean $\mathrm{PetCO}_{2}$. Regarding pulse oximetry researchers interpreted this difference by the fact that the study findings were obtained from critically ill pediatric patients; the most likely group of patients to exhibit clinical conditions that adversely affect pulse oximetry accuracies such as hypoxemia and hypotension as reported by [10] who studied comparison between pulse oximeters and arterial oxygen saturation in critically ill children. Moreover, another explanation 
that pulse oximeter manufacturers provide data from studies that have been extensively performed on the accuracy of pulse oximetry in various adult and pediatric patients and them stated that in critically ill patients with $\mathrm{SaO}_{2}$ values of $90 \%$ or higher, the mean difference between $\mathrm{SpO}_{2}$ and $\mathrm{SaO}_{2}$ is less than $2 \%$ however, worsen when $\mathrm{SaO}_{2}$ is lower than $90 \%$ [16\&17].This compatible with the mean difference observed between $\mathrm{SpO}_{2}$ and $\mathrm{SaO}_{2}$ in the current study as oxygenation status was more than $90 \%$.As well, regarding capnography there are clinical conditions that occur from general anesthesia and cardiac surgical correction and cause ventilationperfusion(V/Q) mismatching such as pulmonary congestion and atelectasis which affecting on capnography accuracy supported by [18] study who evaluate the difference between $\mathrm{ETCO}_{2}$ and $\mathrm{PaCO}_{2}$ in anaesthetized patients and concluded that the difference between $\mathrm{PaCO}_{2}$ and $\mathrm{ETCO}_{2}$ can be explained with the theory of ventilation-perfusion mismatch which can occur in patients who are given general anesthesia or have lung diseases. Moreover, another explanation that the difference observed between $\mathrm{PaCO}_{2}$ and $\mathrm{PetCO}_{2}$ is congruent with the fact that PETC $\mathrm{O}_{2}$ physiologically is approximately $2-5 \mathrm{mmHg}$ lower than $\mathrm{PaCO}_{2}$ so that even in the healthy lung, the difference between $\mathrm{PaCO}_{2}$ and $\mathrm{ETCO}_{2}$ is not usually zero [19-20] and this compatible with the mean difference observed between $\mathrm{EtCO}_{2}$ and $\mathrm{PaCO}_{2}$ in the current study.

Therefore, the difference between the two measurements is a fact that must be taken in consideration and the mean $\left(\mathrm{PaCO}_{2}\right.$ $\left.\mathrm{PetCO}_{2}\right)$ difference, as well as the mean $\left(\mathrm{SaO}_{2}-\mathrm{SpO}_{2}\right)$ difference that observed in current study closely approximates the true physiologic difference and consistent with previously published values.

Further assessment revealed that there was a significant positive correlation was found between two methods of measuring oxyhemoglobin saturation and those two methods of measuring carbon dioxide partial pressure for all studied readings.

Regarding pulse oximetry, because the oxygenation status of the studied subjects in the current study was more than $90 \%$ so that, several studies in agreement with the current study finding as, they have shown consistently satisfactory correlation between $\mathrm{SaO}_{2}$ and $\mathrm{SpO}_{2}$ readings and less difference was found between two techniques in saturation range from $80-100 \%$ such as the study conducted by [21] on the accuracy of pulse oximetry in children. As well, a study was done by [10] who studied the comparison between pulse oximeters and arterial oxygen saturation in critically ill children.

Regarding capnography, previous studies that evaluate the predictive capability of end tidal carbon dioxide monitoring in different clinical settings are in agreement with the current study findings and have shown that $\mathrm{EtCO}_{2}$ is correlated highly withPaCO , they concluded that $\mathrm{EtCO}_{2}$ monitoring displayed a good validity to predict $\mathrm{PaCO}_{2}$ and its use may reduce the need for repeated ABG analysis such as a study observed by [9] whoevaluated the relationship between $\mathrm{PaCO}_{2}$ and $\mathrm{EtCO}_{2}$ in critically ill mechanically ventilated neonates and children. As well, in a study done by [22]. on the correlation between $\mathrm{PaCO}_{2}$ and $\mathrm{EtCO}_{2}$ in mechanically ventilated patients.However, other study findings have indicated a poor correlation between $\mathrm{ETCO}_{2}$ with $\mathrm{PaCO}_{2}$ such as a study observed by [23] who studied noninvasive monitoring of carbon dioxide in infants and children with congenital heart disease, they reported that $\mathrm{ETCO}_{2}$ measurement not accurate predictor of $\mathrm{PaCO}_{2}$ in infants and children congenital heart disease especially, in patients with cyanotic but, this study in contrast with the criteria of subjects in the present study as the studied subjects had done surgical correction forcongenital heart defects.

The researchers investigated a number of demographic and clinical variables presumed to affect ventilation and oxygenation and the findings showed that heart rate had a significant effect on differences between $\mathrm{SaO}_{2}-\mathrm{SPO}_{2}$ whereas tachycardia was associated with low mean $\mathrm{SaO}_{2}-\mathrm{SPO}_{2}$ difference compared with normal heart rate. The researchers interpreted that by the fact that post-operative cardiovascular support is frequently being used in children undergoing heart surgery to improve cardiac output, so the majority of patients were associated with tachycardia as stroke volume in pediatric is rate dependent [24].

The current findings also revealed that PIP has a significant effect on the mean difference between $\left(\mathrm{SaO}_{2}-\mathrm{SPO}_{2}\right)$ and $\left(\mathrm{PaCO}_{2}\right.$ - PetCO $\mathrm{C}_{2}$ ) since, high PIP was associated with the highest mean difference. The researchers interpreted that by the fact that the introduction of positive pressure into the thoracic cavity reduces systemic venous return as a result of progressive increases in mean airway pressure which affects cardiovascular function by produces changes in systemic and pulmonary blood flow [25].

Moreover, the current study found that the difference between $\left(\mathrm{SaO}_{2}-\mathrm{SPO}_{2}\right)$ readings significantly affected by $\mathrm{PaO}_{2}$ values where the high difference between $\left(\mathrm{SaO}_{2}-\mathrm{SPO}_{2}\right)$ readings affected by low $\mathrm{PaO} 2$ these can interpret with low $\mathrm{PaO}_{2}$ values are associated with low $\mathrm{SaO}_{2}$ values related to their relationship through the oxygen dissociation curve [6]. Additionally, it was noticed that $\mathrm{SaO}_{2}$ has a significant effect on the mean $\mathrm{SaO}_{2}-\mathrm{SPO}_{2}$ difference since, highest mean $\mathrm{SaO}_{2}-\mathrm{SPO}_{2}$ difference was associated with $\mathrm{SaO}_{2}$ less than 95\%. This in agreement with [26] findings who reported that as SaO2decrease, the higher the rate of disturbances which may occur in accuracy between $\mathrm{SpO}_{2}$ and $\mathrm{SaO}_{2}$ measurements.

On the other side, it was found that $\mathrm{PaO} 2$ has a significant effect on the mean $\left(\mathrm{PaCO}_{2}-\mathrm{PetCO}_{2}\right)$ difference since high $\mathrm{PaO}_{2}$ was associated with the lowest $\left(\mathrm{PaCO}_{2}-\mathrm{PetCO}_{2}\right)$ difference. These finding may be attributed to the fact that increase $\mathrm{PaO}_{2}$ lead to relaxing the pulmonary vasculature by decreasing pulmonary vascular resistance (PVR) to improve pulmonary blood flow [27]. This in agreement with [28] findings who studied pulse oximetry and capnography in lung function laboratories.

Finally, current study findings also revealed that $\mathrm{SpO}_{2}$ value has a significant effect on the difference between $\left(\mathrm{SaO}_{2}-\mathrm{SPO}_{2}\right)$ and the highest mean $\mathrm{SaO}_{2}-\mathrm{SpO}_{2}$ difference was associated withSp02less than 95\%. This is in agreement with the findings of [15] who study the efficacy of non-invasive monitoring of arterial oxygen saturation and carbon dioxide partial pressure in mechanically ventilated 
patients and pointed out that lack of pulse oximeter accuracy was found, as $\mathrm{SpO}_{2}$ values decreased.

It was also found that the $\mathrm{PetCO}_{2}$ value has a significant effect on the difference between $\left(\mathrm{PaCO}_{2}-\mathrm{PetCO}_{2}\right)$ readings whereas the highest mean $\mathrm{PaCO}_{2}-\mathrm{PetCO}_{2}$ difference was associated with $\mathrm{PetCO}_{2}$ less than $35 \mathrm{mmHg}$, this finding may be attributed to the fact that $\mathrm{PaCO}_{2}-\mathrm{PetCO}_{2}$ difference increased with decrease in $\mathrm{PetCO}_{2}$ values an increase in $\mathrm{PetCO}_{2}$ is almost always due to an increase in $\mathrm{PaCO}_{2}$ however, a decrease in $\mathrm{PetCO}_{2}$ doesn't necessarily correspond to a decrease in $\mathrm{PaCO}_{2}$ as in critically ill patients $\mathrm{PetCO}_{2}$ can be significantly affected with cardiopulmonary perfusion alterations which result in changes in the ventilation/perfusion matching and increase difference between $\mathrm{PaCO}_{2}-\mathrm{PetCO}_{2}$ readings [29] this is in agreement with[11] study on arterial to $\mathrm{EtCO}_{2}$ differences in infants and children.

As well, the highest mean $\mathrm{PaCO}_{2}-\mathrm{PetCO}_{2}$ difference was associated with $\mathrm{PetCO}_{2}$ more than $45 \mathrm{mmHg}$, this finding is in agreement with [15] findings who study efficacy of non-invasive monitoring of arterial oxygen saturation and carbon dioxide partial pressure in mechanically ventilated patients and reported that the efficacy of capnography decreased when $\mathrm{PetCO}_{2}$ more than $45 \mathrm{mmHg}$ because this almost associated with patients having underlying lung impairment in which affected lungs are unable to ventilate all retained $\mathrm{CO}_{2}$ in the blood which in turn increase difference between the two measurements.

\section{Conclusion and Recommendation}

This study demonstrates the utility of $\mathrm{SpO}_{2}$ and $\mathrm{EtCO}_{2}$ values as a predictor for $\mathrm{SaO}_{2}$ and $\mathrm{PaCO}_{2}$ in the clinical assessment of pediatric patients after cardiac surgeries. Though $\mathrm{SpO}_{2}$ and $\mathrm{EtCO}_{2}$ monitoring do not replace blood gas assessment it can serve as an important adjunct in the clinical management of pediatric patients and could lower the need for frequent invasive ABG sampling not replaces in addition to provides continuous information instead of measurements at a specific point. Further study should continue to define the utility of $\mathrm{SpO}_{2}$ and $\mathrm{EtCO}_{2}$ as a measure of $\mathrm{SaO}_{2}$ and $\mathrm{PaCO}_{2}$ in pediatric patients with different body system alterations.

\section{References}

1. Karakitsos D, El Barbary M, Gillman LM, Papalois A,Shiloh A (2014) Critical care and perioperative monitoring. The Scientific World Journal.

2. Bronicki RA, Chang AC (2011) Management of the postoperative pediatric cardiac surgical patient. Crit Care Med 39(8): 1974-1984.

3. Roberts JR, Hedges JR (2013) Roberts and Hedges' Clinical Procedures in Emergency Medicine E-Book. Elsevier Health Sciences.

4. Danckers M, Fried ED (2013) Arterial Blood Gas Sampling. Medscape reference drugs, disease and procedures pp. 19-20.

5. Cheifetz IM (2013) Advances in monitoring and management of pediatric acute lung injury. Pediatr Clin North Am 60(3): 621-639.

6. Fouzas S, Priftis K N, Anthracopoulos MB (2011) Pulse oximetry in pediatric practice. Pediatrics 128(4):740-752.

7. Ortega R, Connor C, Kim S, Djang R,Patel K (2012) Monitoring ventilation with capnography. The New England journal of medicine 367(19): e27.

8. Rowan CM, Speicher RH, Hedlund T, Ahmed SS, Swigonski NL (2015) Implementation of continuous capnography is associated with a decreased utilization of blood gases. Journal of clinical medicine research 7(2): 71-75.

9. Mehta H, Kashyap R, Trivedi S (2014) Correlation of end tidal and arterial carbon dioxide levels in critically ill neonates and children. Indian J Crit Care Med 18(6): 348-353.

10. Jose B, Lodha R, Kabra SK (2014) Comparison of two new generation pulse oximeters with arterial oxygen saturation in critically ill children. The Indian Journal of Pediatrics 81(12): 1297-1301.

11. Ickx B, Dolomie JO, Benalouch M, Melot C \& Lingier P (2015) Arterial to End-Tidal Carbon Dioxide Tension Differences in Infants and Children. Journal of Anesthesia \& Clinical Research 6(2): 1-5.

12. Niknafs P, Norouzi E, Bijari BB, Baneshi MR (2015) Can we replace arterial blood gas analysis by pulse oximetry in neonates with respiratory distress syndrome, who are treated according to INSURE protocol? Iran J Med Sci 40(3): 264.

13. Safar H \& El dash H (2015) Pulse Oximetry: Could Wrist and Ankle Be Alternative Placement Sites? Clin Pediatr (Phila) 54(14): 1375-1379.

14. Eipe N \& Doherty DR (2010) A review of pediatric capnography. J Clin Monit Comput 24(4): 261-268.

15. Ali F (2007) Efficacy of Non-invasive Monitoring of Arterial Oxygen Saturation and Carbon Dioxide Partial Pressure in Mechanically Ventilated Patients,MD.Thesis in Critical Care and Emergency, Faculty of Nursing, Alexandria University, Egypt.

16. JubranA (2015) Pulse oximetry. Critical Care 19(1): 272.

17. Nitzan M, Romem A \& Koppel R (2014) Pulse oximetry: fundamentals and technology update. Med Devices (Auckl) 7: 231-239?

18. Husaini J \& Choy YC (2008) End-tidal to arterial carbon dioxide partial pressure difference during craniotomy in anaesthetised patients. Med J Malaysia 63(5): 384-387.

19. Moses JM, Alexander JL \& Agus MS (2009) The correlation and level of agreement between end-tidal and blood gas pCO 2 in children with respiratory distress: a retrospective analysis. BMC pediatrics 9(1): 20.

20. Mc Swain SD, Hamel DS, Smith PB, Gentile MA., Srinivasan S, et al. (2010) End-tidal and arterial carbon dioxide measurements correlate across all levels of physiologic dead space.Respir Care 55(3): 288-293.

21. Ross PA, Newth CJ \& Khemani RG (2014) Accuracy of pulse oximetry in children. Pediatrics 133 (1): 22-29.

22. Razi E, Moosavi GA, Omidi K, Khakpour Saebi A \& Razi A (2012) Correlation of end-tidal carbon dioxide with arterial carbon dioxide in mechanically ventilated patients. Arch Trauma Res 1(2): 58-62.

23. Wilson J, Russo P, Russo J \& Tobias JD (2005) Noninvasive monitoring of carbon dioxide in infants and children with congenital heart disease: end-tidal versus transcutaneous techniques. Journal of intensive care medicine 20(5): 291-295.

24. Roeleveld PP \& De Klerk JCA (2018) The perspective of the intensivist on inotropes and postoperative care following pediatric heart surgery: an international survey and systematic review of the literature. World J Pediatr Congenit Heart Surg 9(1): 10-21.

25. Gupta R \& Rosen D (2016)Paediatric mechanical ventilation in the intensive care unit. BJA Education 16(12): 422-426.]

26. Wilson BJ, Cowan HJ, Lord JA, Zuege DJ \& Zygun DA (2010) The accuracy of pulse oximetry in emergency department patients with severe sepsis and septic shock: a retrospective cohort study. BMC emergency medicine 10(1): 9.

27. Manja V, Lakshminrusimha S \& Cook DJ (2015) Oxygen saturation target range for extremely preterm infants: a systematic review and metaanalysis. JAMA Pediatr 169(4): 332-340.

28. Giner J \& Casan P (2004) Pulse oximetry and capnography in lung function laboratories. Archivos de Bronconeumología 40(7): 311-314.

29. Wheeler DS (2014) Pediatric critical care medicine. HR Wong \& $T \mathrm{P}$ Shanley (Eds.), Springer, Germany. 